Article

\title{
Enzyme-Mediated Quenching of the Pseudomonas Quinolone Signal (PQS): A Comparison between Naturally Occurring and Engineered PQS-Cleaving Dioxygenases
}

\author{
Alba Arranz San Martín ${ }^{1,+} \mathbb{D}$, Jan Vogel ${ }^{2}$, Sandra C. Wullich ${ }^{1, \ddagger}$, Wim J. Quax ${ }^{2}$ (D) and Susanne Fetzner ${ }^{1, *(\mathbb{D})}$ \\ 1 Institute for Molecular Microbiology and Biotechnology, University of Münster, Corrensstraße 3, \\ 48149 Münster, Germany; a_arra01@uni-muenster.de (A.A.S.M.); wullich@uni-muenster.de (S.C.W.) \\ 2 Department of Chemical and Pharmaceutical Biology, Groningen Research Institute of Pharmacy, \\ University of Groningen, Antonius Deusinglaan 1, 9713 AV Groningen, The Netherlands; \\ j.g.t.vogel@rug.nl (J.V.); w.j.quax@rug.nl (W.J.Q.) \\ * Correspondence: fetzner@uni-muenster.de; Tel.: +49-251-83-39824 \\ + Present address: Department of Microbiology and Parasitology, Faculty of Pharmacy, University of Seville, \\ C/Profesor García González 2, 41012 Seville, Spain. \\ ‡ Present address: CureVac, Friedrich-Miescher-Straße 15, 72076 Tübingen, Germany.
}

check for updates

Citation: Arranz San Martín, A.; Vogel, J.; Wullich, S.C.; Quax, W.J.; Fetzner, S. Enzyme-Mediated Quenching of the Pseudomonas Quinolone Signal (PQS): A Comparison between Naturally Occurring and Engineered PQS-Cleaving Dioxygenases.

Biomolecules 2022, 12, 170.

https://doi.org/10.3390/

biom 12020170

Academic Editors: Marco van den Berg and Marco Fraaije

Received: 21 December 2021

Accepted: 18 January 2022

Published: 21 January 2022

Publisher's Note: MDPI stays neutral with regard to jurisdictional claims in published maps and institutional affiliations.

Copyright: (C) 2022 by the authors. Licensee MDPI, Basel, Switzerland. This article is an open access article distributed under the terms and conditions of the Creative Commons Attribution (CC BY) license (https:// creativecommons.org/licenses/by/ $4.0 /)$.

\begin{abstract}
The opportunistic pathogen Pseudomonas aeruginosa employs quorum sensing to govern the production of many virulence factors. Interference with quorum sensing signaling has therefore been put forward as an attractive approach to disarm this pathogen. Here, we analyzed the quorum quenching properties of natural and engineered (2-alkyl-)3-hydroxy-4(1H)-quinolone 2,4dioxygenases (HQDs) that inactivate the P. aeruginosa signal molecule PQS (Pseudomonas quinolone signal; 2-heptyl-3-hydroxy-4(1H)-quinolone). When added exogenously to $P$. aeruginosa cultures, all HQDs tested significantly reduced the levels of PQS and other alkylquinolone-type secondary metabolites deriving from the biosynthetic pathway, such as the respiratory inhibitor 2-heptyl-4hydroxyquinoline N-oxide. HQDs from Nocardia farcinica and Streptomyces bingchenggensis, which combine low $\mathrm{K}_{\mathrm{M}}$ values for PQS with thermal stability and resilience in the presence of P. aeruginosa exoproducts, respectively, attenuated production of the virulence factors pyocyanin and pyoverdine. A delay in mortality was observed when Galleria mellonella larvae were infected with P. aeruginosa suspensions treated with the S. bingchenggensis HQD or with inhibitors of alkylquinolone biosynthesis. Our data indicate that quenching of PQS signaling has potential as an anti-virulence strategy; however, an efficient anti-virulence therapy against $P$. aeruginosa likely requires a combination of agents addressing multiple targets.
\end{abstract}

Keywords: dioxygenase; Galleria mellonella; Pseudomonas aeruginosa; Pseudomonas quinolone signal; quorum quenching; virulence

\section{Introduction}

Pseudomonas aeruginosa is a ubiquitous environmental bacterium and opportunistic pathogen associated with a wide range of nosocomial infections. It typically affects immunocompromised and hospitalized individuals and is a major pathogen associated with pulmonary infections, particularly in patients with cystic fibrosis (CF) [1,2]. Infections caused by $P$. aeruginosa are increasingly difficult to treat due to intrinsic and acquired antibiotic resistances and the spread of antibiotic-resistant strains [3].

Key factors contributing to the pathogenesis of $P$. aeruginosa include the production of a plethora of virulence factors, the formation of biofilms, and its metabolic versatility and high adaptability [1]. Many virulence-associated behaviors are regulated via quorum sensing (QS), a cell-to-cell communication mechanism employed by bacteria to sense and collectively respond to cell density and environmental cues. QS relies on the production 
and detection of diffusible signal molecules termed autoinducers (AI), which are detected by cognate receptor proteins. The AI-receptor complexes typically activate transcription of the gene(s) coding for AI synthesis and trigger population-wide changes in gene expression [4]. In $P$. aeruginosa, the QS network is composed of three interconnected signaling circuits, namely the two $N$-acylhomoserine lactone (AHL) dependent signaling systems las and $r h l$ and the pqs system that relies on particular 2-alkyl-4(1H)-quinolones (AQs) as signal molecules [1,5]. Besides 2-heptyl-3-hydroxy-4(1H)-quinolone (the Pseudomonas quinolone signal, PQS) as a major AQ-type signal of $P$. aeruginosa, its biosynthetic precursor 2-heptyl-4(1H)-quinolone (HHQ) also is an AI of the pqs system. The pqs system is involved, either directly or indirectly, in the regulation of a series of virulence factors, including the redox-active pigment pyocyanin, the siderophore pyoverdine, rhamnolipid biosurfactants, elastase, or hydrogen cyanide $[1,6,7]$. Besides their regulatory role in P. aeruginosa pathogenicity, PQS and HHQ possess additional functionalities. PQS induces the formation of outer membrane vesicles, chelates ferric iron and mediates iron acquisition, activates the oxidative stress response, acts as a stress warning signal, and modulates host immune responses [6-8]. PQS and HHQ repress motility in several bacterial species, and HHQ exhibits bacteriostatic activity [9].

Another product of the AQ biosynthetic pathway, 2-heptyl-4-hydroxyquinoline $N$ oxide (HQNO), does not act as a QS signal molecule but is a major virulence factor, which moreover triggers autolysis of $P$. aeruginosa. As a potent inhibitor of the cytochrome $b c_{1}$ complex, it strongly induces the formation of reactive oxygen species (ROS), leading to disruption of membrane integrity and autolysis. HQNO-mediated release of DNA promotes biofilm formation and antibiotic tolerance [10].

Given the involvement of microbial QS systems in the regulation of virulence factor production, these represent a potential target for anti-virulence therapies [11]. Interference with QS signaling, also termed quorum quenching (QQ), may be achieved using small molecules that inhibit the biosynthesis, detection, or transduction of the signal molecule, as well as through the use of QQ enzymes that catalyze the inactivation of the signal molecules [12]. Numerous QQ enzymes that target AHL signal molecules have been described in the literature, whereas the number of enzymes known to inactivate other types of signal molecules is limited [13].

Within the huge superfamily of $\alpha / \beta$-hydrolase fold proteins, the subfamily of 3hydroxy-4(1H)-quinolone 2,4-dioxygenases (HQDs) comprises cofactor-less enzymes that catalyze the cleavage of the heterocyclic ring of 3-hydroxy-4(1H)-quinolones [14] (Figure 1). Among them, HodC (1H-3-hydroxy-4-oxoquinaldine 2,4-dioxygenase) from Arthrobacter sp. Rue61a was the first enzyme described to cleave PQS into carbon monoxide and $N$ octanoylanthranilic acid [15]. Even though its activity toward PQS is low, as its physiological substrate is 3-hydroxy-2-methyl-4 $(1 H)$-quinolone (an intermediate in the degradation of 2-methylquinoline), the addition of HodC to P. aeruginosa cultures quenched AQ production [15]. In contrast to HodC, the dioxygenases AqdC1 from Rhodococcus erythropolis BG43 and AqdC of Mycobacteroides abscessus subsp. abscessus preferentially cleave PQS [16]. These enzymes are part of a PQS-inducible pathway that converts HHQ to octanoate and anthranilic acid, which can be funneled into central metabolic pathways $[17,18]$.<smiles>[R]c1[nH]c2ccccc2c(=O)c1O</smiles>

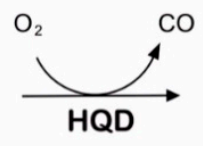<smiles>[R]C(=O)Nc1ccccc1C(=O)O</smiles><smiles>[R5]OCC([R])CC</smiles>

Figure 1. Cleavage of (2-alkyl-)3-hydroxy-4(1H)-quinolones as described for the subfamily of (2-alkyl)3-hydroxy-4(1H)-quinolone 2,4-dioxygenases (HQDs) [14]. HQ, 3-hydroxy-4(1H)-quinolone; PQS, Pseudomonas quinolone signal.

A main drawback of using HodC or AqdC for potential application as QQ enzymes is their susceptibility to proteolytic degradation or denaturation in adverse physicochemical 
conditions, respectively $[15,16]$. To improve the robustness of mycobacterial AqdC, a recent study used computational library design to predict stabilizing amino acid replacements and to engineer more thermostable variants [19].

Further members of the HQD family active toward PQS have been recently identi-

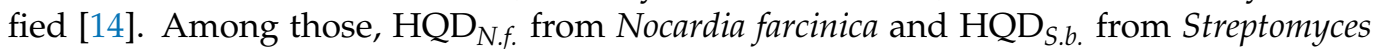
bingchenggensis showed higher affinity and catalytic efficiency toward PQS than AqdC and rhodococcal AqdC1, making them promising candidates for QQ studies. In the present study, we compared the QQ properties of two engineered AqdC proteins and the newly described PQS dioxygenases $\mathrm{HQD}_{N . f .}$ and $\mathrm{HQD}_{S . b}$. to those of wild-type AqdC. To this end, we analyzed the AQ levels and production of the QS-regulated virulence factors pyocyanin, pyoverdine, rhamnolipids, and elastase by P. aeruginosa in the presence of the QQ enzymes. Additionally, the virulence of P. aeruginosa incubated with the PQS dioxygenases was assessed in a Galleria mellonella infection model that enables the precise injection of defined bacterial loads directly into the hemocoel. For comparison, synthetic inhibitors targeting PqsD, a key enzyme of AQ biosynthesis, were included in the G. mellonella studies.

\section{Materials and Methods}

\subsection{Chemicals}

HHQ, HQNO, and PQS were acquired from Sigma Aldrich (Schnelldorf, Germany). PqsD inhibitors (compounds 19 and 62) [20,21] were kindly provided by Dr. Empting and Prof. Hartmann, Helmholtz Institute for Pharmaceutical Research Saarland (HIPS), Saarbrücken, Germany.

\subsection{Bacterial Strains, HQD Enzymes, and Plasmids}

HQDs were recombinantly produced in E. coli BL21(DE3) [22] or E. coli TOP10 (Invitrogen). The proteins, source organisms, and expression plasmids used are listed in Table 1. Assays to determine quenching of virulence factor production by PQS dioxygenases were performed with $P$. aeruginosa strains PAO1 (Nottingham strain, Holloway collection) and PA14 [23].

Table 1. (2-Alkyl-)3-Hydroxy-4(1H)-quinolone 2,4-dioxygenases (HQDs) examined in the present study. Expression plasmids and the respective source organisms of the enzymes are indicated. European Nucleotide Archive (ENA) accession IDs of the genes are also included.

\begin{tabular}{lcccc}
\hline Protein & Source Organism & ENA ID & Expression Plasmid & Reference \\
\hline HodC & $\begin{array}{c}\text { Arthrobacter sp. } \\
\text { Rue61a }\end{array}$ & CAA75080.1 & pET23a::hodC & {$[24]$} \\
\hline AqdC & $\begin{array}{c}\text { Mycobacteroides } \\
\text { abscessus ATCC 19977 }\end{array}$ & CAM60402.1 & pET28b::his8-TEV-aqdC & {$[17]$} \\
\hline AqdC $^{\text {V }}$ & $\begin{array}{c}\text { Mycobacteroides } \\
\text { abscessus ATCC 19977 }\end{array}$ & CAM60402.1 & $\begin{array}{c}\text { pBAD::his8-tev-aqdC-G40K- } \\
\text { A134L-G220D-Y238W }\end{array}$ & {$[19]$} \\
\hline AqdC $^{\text {VIII }}$ & $\begin{array}{c}\text { Mycobacteroides } \\
\text { abscessus ATCC 19977 }\end{array}$ & CAM60402.1 & $\begin{array}{c}\text { pBAD::his8-tev-aqdC- } \\
\text { G40K-G220D-Y238W }\end{array}$ & {$[19]$} \\
\hline HQD $_{\text {N.f. }}$ & $\begin{array}{c}\text { Nocardia farcinica } \\
\text { IFM 10152 }\end{array}$ & BAD60071.1 & pET28b::his8-TEV-HQD & {$[14]$} \\
\hline HQD $_{\text {S.b. }}$ & $\begin{array}{c}\text { Streptomyces } \\
\text { bingchenggensis BCW-1 }\end{array}$ & ADI1806.1 & pET28b::his8-TEV-HQD & {$[14]$} \\
\hline
\end{tabular}

\subsection{Heterologous Production and Purification of Dioxygenases}

Recombinant E. coli BL21 strains were grown aerobically at $37^{\circ} \mathrm{C}$ in LB with appropriate antibiotics. Cultures of E. coli BL21(DE3) harboring pET expression plasmids were supplemented with $0.25 \mathrm{mM}$ IPTG at an $\mathrm{OD}_{600 \mathrm{~nm}}$ of $0.5-0.8$ and incubated for approximately $16 \mathrm{~h}$ at $15^{\circ} \mathrm{C}$. Cultures of E. coli TOP10 with recombinant pBAD plasmids were supplemented at an $\mathrm{OD}_{600 \mathrm{~nm}}$ of $0.6-0.9$ with L-arabinose (final concentration of $0.2 \%$ 
$(w / v))$ and incubated for $5-6 \mathrm{~h}$ at $24{ }^{\circ} \mathrm{C}$. Cells were harvested by centrifugation, resuspended in lysis buffer ( $300 \mathrm{mM} \mathrm{NaCl}, 20 \mathrm{mM}$ Tris, 0.05\% NP-40, pH 8.0), and disrupted by sonication. Cell debris was removed by centrifugation $\left(18,000 \mathrm{rpm}, 40 \mathrm{~min}, 4{ }^{\circ} \mathrm{C}\right)$ and the supernatant was filtered. Proteins were purified to electrophoretic homogeneity (Supplementary Materials, Figure S1) by Ni-NTA affinity chromatography (elution buffer: $20 \mathrm{mM}$ Tris/ $\mathrm{HCl}, \mathrm{pH} \mathrm{8,} 300 \mathrm{mM} \mathrm{NaCl}, 300 \mathrm{mM}$ imidazole) and stored in a buffer containing $20 \mathrm{mM}$ Tris and $10 \%$ glycerol $\left(\mathrm{pH} \mathrm{8.0)}\right.$ at $-80{ }^{\circ} \mathrm{C}$ until required. Quantification of proteins was performed using the Bradford method, with bovine serum albumin as the standard protein, or spectrophotometrically using the NanoPhotometer ${ }^{\circledR}$ N60 (IMPLEN, Inc., Westlake Village, CA, USA).

\subsection{Enzyme Assay}

The catalytic activity of the proteins was assessed spectrophotometrically by measuring PQS consumption at $337 \mathrm{~nm}$ and $30^{\circ} \mathrm{C}$. The assays contained up to $20 \mu \mathrm{M}$ PQS in buffer (50 mM Tris, 2 mM EDTA, 10\% PEG 1500, pH 8.0). At the specified conditions, the extinction coefficient of PQS is $10,169 \mathrm{M}^{-1} \mathrm{~cm}^{-1}$. One unit of enzyme activity was defined as the amount of enzyme converting $1 \mu \mathrm{mol}$ of PQS per minute under the conditions of this assay.

\subsection{Cultivation of P. aeruginosa in the Presence of Quorum Quenching Enzymes}

Overnight cultures of P. aeruginosa PAO1 and PA14 in LB medium were diluted to an $\mathrm{OD}_{600}$ of 0.05 in $30 \mathrm{~mL}$ of fresh medium and incubated at $37^{\circ} \mathrm{C}$ under vigorous shaking $(140 \mathrm{rpm})$ throughout the whole experiment. Each of the enzymes $(0.3 \mathrm{U} / \mathrm{mL})$ was added to the growing cultures after $2 \mathrm{~h}$ of incubation. P. aeruginosa cultures supplemented with the equivalent amount of buffer (20 mM Tris buffer ( $\mathrm{pH} 8), 10 \%(v / v)$ glycerol) were used as a control. To determine the production of AQs and virulence factors, culture samples were taken $6 \mathrm{~h}$ and $24 \mathrm{~h}$ after enzyme or buffer addition.

\subsection{Determination of $A Q$ Levels}

AQ levels in P. aeruginosa cultures were determined with a Hitachi EZchrom Elite HPLC system. Culture samples $(500 \mu \mathrm{L}$ each) were extracted three times with $500 \mu \mathrm{L}$ ethyl acetate (acidified with $1 \mathrm{~mL} \mathrm{~L}^{-1}$ acetic acid), dried to completion, re-dissolved in acidified $(0.1 \%(w / v)$ citric acid) methanol, and separated by HPLC on a Eurospher II 100-5 C18 column (Knauer) at $35{ }^{\circ} \mathrm{C}$ using a linear gradient (within $40 \mathrm{~min}$ ) from $60 \%$ methanol in water with $0.1 \%(w / v)$ citric acid to $100 \%$ methanol with $0.1 \%(w / v)$ citric acid at a flow rate of $0.5 \mathrm{~mL} \mathrm{~min}^{-1}$. A diode array detector (L-2450 LaChrome Elite, Merck Hitachi) was used to record the light absorption spectra of eluted compounds. PQS, HHQ, and HQNO were used as reference compounds for calibration.

\subsection{Quantification of Virulence Factors}

Pyocyanin content was quantified spectrophotometrically at $520 \mathrm{~nm}$ after chloroform extraction from the culture supernatant samples, as described by Essar et al. [25]. Pyoverdine levels in culture supernatants were determined by measuring the absorption at $405 \mathrm{~nm}$ [26]. The orcinol method, as described by Wilhelm et al. [27] was used for rhamnolipid quantification. Elastolytic activity in culture supernatants was analyzed with the elastin Congo Red assay [28].

\subsection{Galleria mellonella Infection Model}

G. mellonella research grade larvae (TruLarv ${ }^{\mathrm{TM}}$, Biosystems Technology Ltd., Crediton, Devon, EX17 3LF, UK) were stored in the dark at $15^{\circ} \mathrm{C}$. Overnight cultures of $P$. aeruginosa PAO1 were diluted in fresh $\mathrm{LB}$ medium to an $\mathrm{OD}_{600}$ of 0.02 , and bacterial cultures were grown at $37^{\circ} \mathrm{C}$ under vigorous shaking. Cells were washed with sterile PBS and diluted to $10^{3} \mathrm{CFU} / \mathrm{mL}$. Afterwards, the enzymes of interest (20 units $\left./ \mathrm{mL}\right)$, PqsD inhibitors $(100 \mu \mathrm{M})$, or the equivalent amount of PBS were added to $950 \mu \mathrm{L}$ of bacteria and incubated at $30{ }^{\circ} \mathrm{C}$ 
for $1 \mathrm{~h}$. Ten microliters of the suspension were then injected into the last proleg of a larva. Non-treated larvae were included as a negative control. In addition, larvae were injected with PBS to assess the physical trauma produced during the injection process. Following injection, G. mellonella larvae were incubated at $30^{\circ} \mathrm{C}$ and examined every $8 \mathrm{~h}$. Larvae were considered dead when not reacting to touch.

\subsection{Statistical Analysis}

Statistical differences were analyzed using GraphPad Prism Version 6.0 (GraphPad Software Inc., La Jolla, CA, USA).

\section{Results}

\subsection{Catalytic Half-Lives of PQS Dioxygenases}

To compare the stability of the newly identified dioxygenases $\mathrm{HQD}_{N . f .}$ and $\mathrm{HQD}_{S . b}$. to that of wild-type and engineered AqdC variants, purified proteins were incubated at $37^{\circ} \mathrm{C}$ and residual activities were determined. The enzymatic activity of both AqdC and

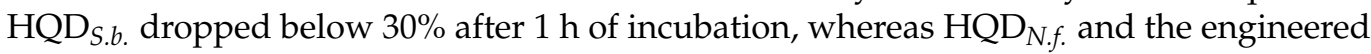
variant $\mathrm{AqdC}^{\mathrm{V}}$ retained more than $80 \%$ of activity after this time interval (Figure 2). Short half-lives of the enzymes are a limiting factor for their potential application as QQ agents.

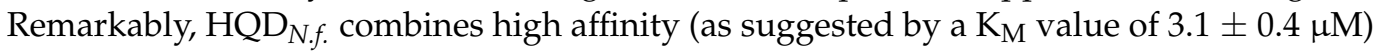
and high catalytic efficiency toward PQS (Table S1) with high stability (Figure 2). The $\mathrm{AqdC}^{\mathrm{V}}$ protein showed an even longer half-life (Figure 2); however, its comparatively high $\mathrm{K}_{\mathrm{M}}$ value of $22.1 \pm 4.1 \mu \mathrm{M}$ (Table S1) may limit its applicability as a QQ enzyme. HQD S.b. which exhibits the lowest $\mathrm{K}_{\mathrm{M}}$ towards PQS among the enzymes tested (Table S1), seems to be very thermosensitive in PBS, as reflected by its short half-life.

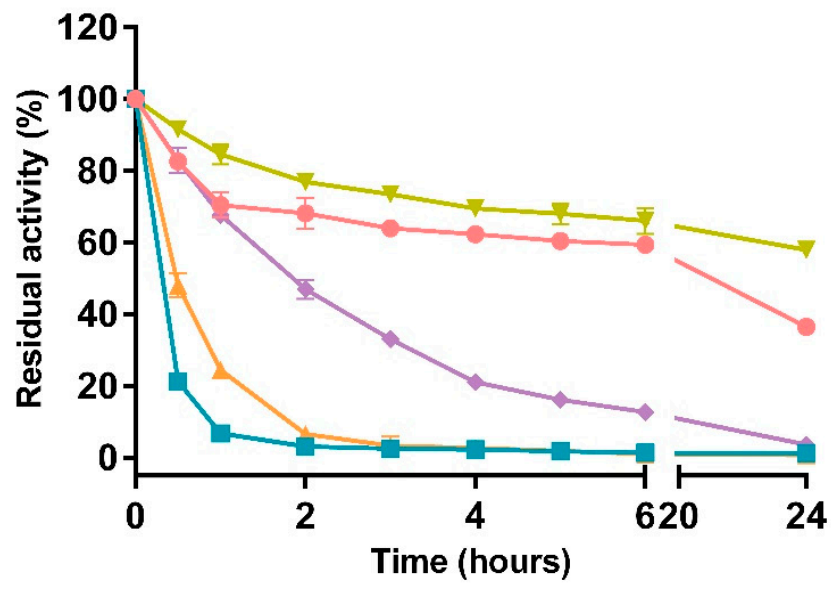

\begin{tabular}{ccc}
\hline & Dioxygenase & \multicolumn{1}{c}{$\mathrm{t}_{1 / 2}(\mathrm{~h})$} \\
\hline- & AqdC & $0.49 \pm 0.03$ \\
- & AqdC $^{\vee}$ & $30.29 \pm 0.06$ \\
- & AqdC $^{\mathrm{VIII}}$ & $1.87 \pm 0.03$ \\
- & $\mathrm{HQD}_{\text {N.f. }}$ & $15.71 \pm 0.26$ \\
- & $\mathrm{HQD}_{\text {S.b. }}$ & $0.22 \pm 0.01$ \\
\hline
\end{tabular}

Figure 2. Effect of temperature on the enzymatic activity of PQS dioxygenases. Enzyme solutions $\left(0.2 \mathrm{mg} \mathrm{mL}^{-1}\right)$ in PBS ( $\mathrm{pH} 7.5$ ) were incubated at $37^{\circ} \mathrm{C}$, and residual catalytic activities of samples withdrawn at appropriate time intervals were measured using the standard enzyme assay. The catalytic half-life ( $t_{\frac{1}{2}}$ in [h]; period required for the enzymatic activity to decrease to half of its initial value) was determined by fitting the data to the one-phase exponential decay model, with the plateau parameter adjusted to a constant value of zero, using GraphPadPrism 6 software. Data represent the average \pm SD from triplicate experiments.

\subsection{PQS Dioxygenases in Contrast to HodC Are Not Inactivated by P. aeruginosa Exoproducts}

$P$. aeruginosa is a prolific producer of several extracellular enzymes with proteolytic activity, with the metalloprotease LasB as the most abundant protease. Previous studies have shown that HodC is rapidly inactivated in P. aeruginosa cultures or culture supernatants, and LasB was identified to be responsible for degradation of this enzyme [24]. Interestingly, all PQS dioxygenases tested resisted inactivation by culture supernatants of $P$. aeruginosa PA14 (Figure 3). Remarkably, even a stabilizing effect by the supernatant of strain PA14 
was observed for $\mathrm{HQD}_{\text {S.b. }}$, which in PBS (Figure 2) and LB medium (Figure 3) undergoes rapid thermal inactivation. Combined with its favorable kinetic properties (Table S1), this feature makes $\mathrm{HQD}_{\text {S.b. }}$ a still attractive candidate enzyme for $\mathrm{QQ}$ assays.

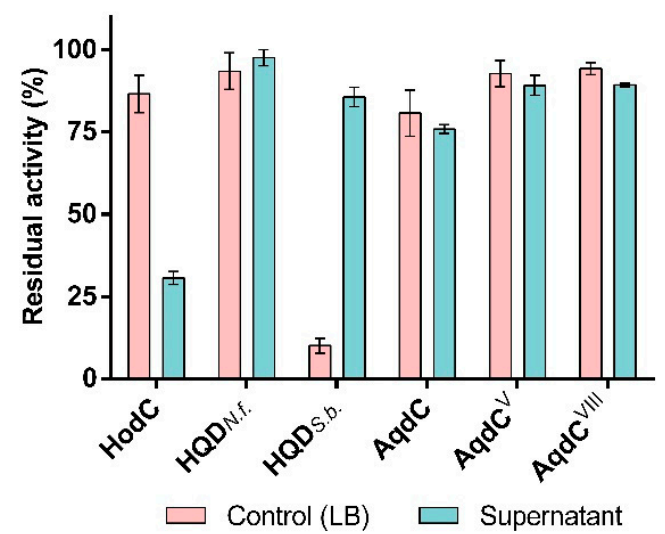

Figure 3. Effect of P. aeruginosa PA14 culture supernatant on enzymatic activity of PQS dioxygenases. HodC, which has previously been shown to be inactivated by the extracellular protease LasB, was included for comparison (see also ref. [24]). $500 \mu \mathrm{L} / \mathrm{mL}$ cell-free stationary phase culture supernatant of $P$. aeruginosa PA14 or $500 \mu \mathrm{L} / \mathrm{mL}$ LB medium (control) were incubated with the enzyme of interest $(1 \mathrm{U} / \mathrm{mL})$ in buffer $(20 \mathrm{mM}$ Tris, $\mathrm{pH} 8.0)$ at $37{ }^{\circ} \mathrm{C}$. Residual catalytic activities after $30 \mathrm{~min}$ of incubation were determined in the standard enzyme assay. Data represent the mean $\pm \mathrm{SD}$ from at least three replicates.

\subsection{PQS Dioxygenases from N. farcinica and S. bingchenggensis Quench $A Q$ and Virulence Factor Production}

In order to compare the quenching effects of different PQS dioxygenases on the production of AQs and selected virulence factors by P. aeruginosa, the same amount of enzyme units was added to growing cultures of P. aeruginosa PAO1 or PA14. The addition of the enzymes did not affect bacterial growth (data not shown). Besides the more thermostable AqdC variants $\mathrm{AqdC}^{\mathrm{V}}$ and $\mathrm{AqdC} \mathrm{VIII}^{\mathrm{VI}}, \mathrm{HQD}_{\text {N.f. }}$ and $\mathrm{HQD}_{S . b .}$. were chosen because of their low $\mathrm{K}_{\mathrm{M}}$ values for PQS (Table S1), combined with intrinsic thermostability $\left(\mathrm{HQD}_{N . f .}\right)$ or resilience in $P$. aeruginosa culture supernatant $\left(\mathrm{HQD}_{S . b .}\right)$. All $\mathrm{PQS}$ dioxygenases very effectively quenched PQS levels, as indicated by the data collected 6 and $24 \mathrm{~h}$ after enzyme addition to the cultures (Figure $4 a, b$ ). Considering the comparatively high $K_{M}$ value and poor catalytic efficiency of $\mathrm{AqdC}^{\mathrm{V}}$ (Table S1), it is remarkable that PQS was fully depleted in the respective samples. Levels of HHQ and HQNO were also significantly reduced in all cultures, likely due to a decrease in the expression of the $A Q$ biosynthetic operon $p q s A B C D E$ under deficiency of the major autoinducer PQS. In the PAO1 cultures, $\mathrm{HQD}_{N . f .}$ and $\mathrm{HQD}_{\text {S.b. }}$ were more efficient in attenuating $\mathrm{HHQ}$ production than the engineered AqdC variants. Addition of PQS dioxygenases to PAO1 and PA14 cultures quenched pyocyanin and pyoverdine levels, with $\mathrm{HQD}_{N . f .}$ and $\mathrm{HQD}_{S . b \text {. }}$ eliciting the strongest attenuation in PAO1 cultures (Figure 4c,d). The PQS dioxygenases only weakly (if at all) affected the levels of elastase and rhamnolipids; however, decreases in response to $\mathrm{HQD}_{S . b \text {. }}$ and also $\mathrm{HQD}_{N . f .}$ were observed in some samples (Figure $4 \mathrm{c}, \mathrm{d}$ ). 


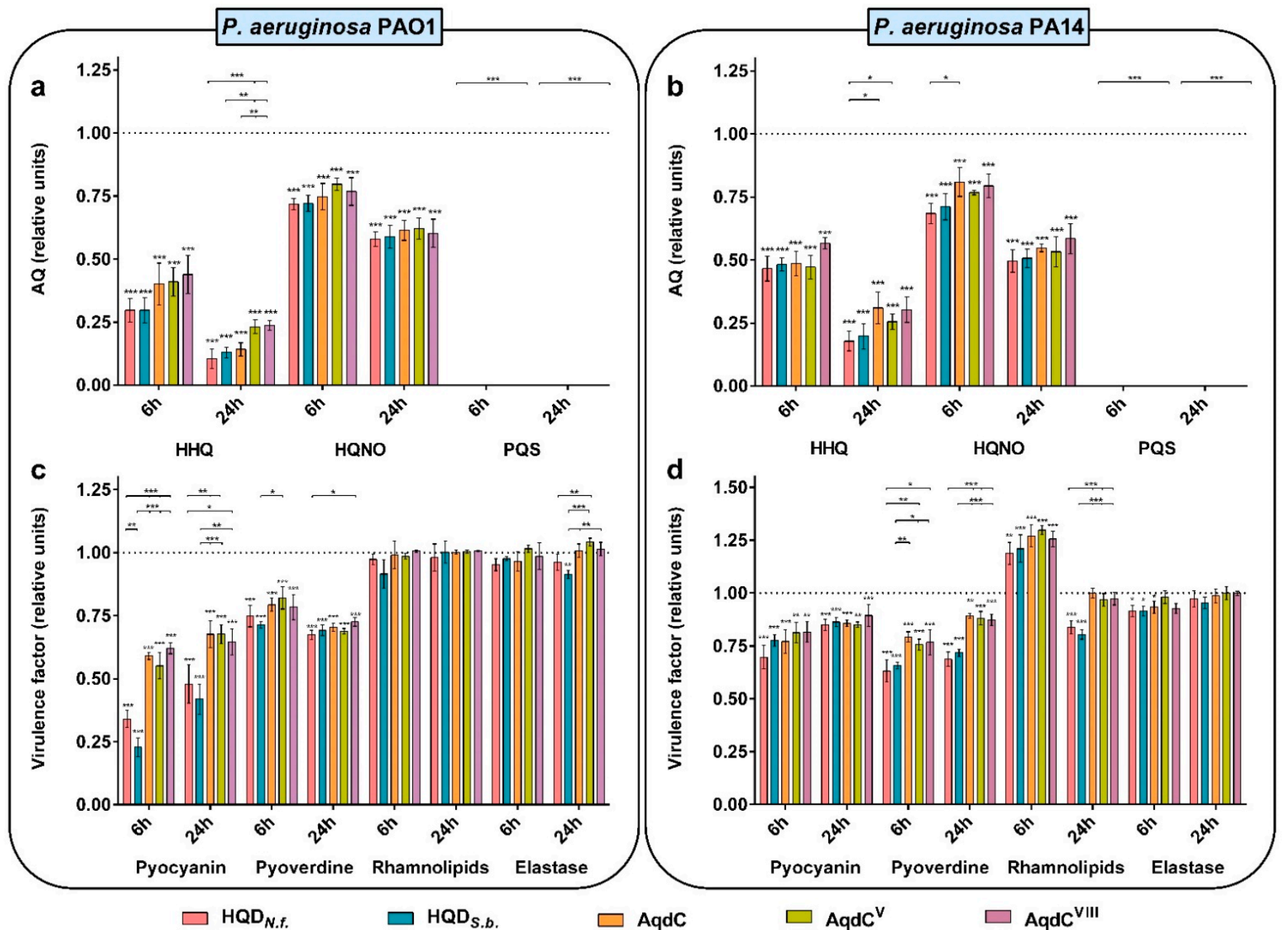

Figure 4. AQ levels $(\mathbf{a}, \mathbf{b})$ and virulence factor production $(\mathbf{c}, \mathbf{d})$ in growing cultures of $P$. aeruginosa PAO1 (a,c) and P. aeruginosa PA14 (b,d) after the addition of $0.3 \mathrm{U} / \mathrm{mL}$ of the PQS-cleaving dioxygenases $\mathrm{HQD}_{N . f .}, \mathrm{HQD}_{\text {S.b., }} \mathrm{AqdC} \mathrm{AqdC}^{\mathrm{V}}$, or AqdC ${ }^{\mathrm{VIII}}$. P. aeruginosa cultures supplemented with the equivalent amount of buffer were used as a control. Levels of AQs and virulence factors in samples of $P$. aeruginosa control cultures were set to 1 at each of the sampling times indicated $(6$ and $24 \mathrm{~h})$ and are represented by a dotted line. Data represent the mean \pm SD of three independent biological replicates. Statistical analysis was performed using ANOVA/Tukey HSD, ${ }^{*} p<0.05,{ }^{* *} p<0.01,{ }^{* * *} p<0.001$.

3.4. PQS Dioxygenase from S. bingchenggensis, as Well as Small Molecule Inhibitors of AQ Biosynthesis, Enhance G. mellonella Survival upon Infection with P. aeruginosa PAO1

To test whether exogenous addition of PQS dioxygenases is able to affect the pathogenicity of $P$. aeruginosa in an in vivo infection model, we analyzed the mortality of G. mellonella larvae in response to injection of $P$. aeruginosa suspensions that were incubated in enzyme solution. As shown in Figure 5a, treatment of P. aeruginosa PAO1 with the PQS dioxygenase $\mathrm{HQD}_{S . b}$. prior to injection into the larvae led to an increase $(p=0.0443)$ in overall survival as compared with the $P$. aeruginosa-infected control. Incubation of the pathogen with $\mathrm{HQD}_{N . f \text {. }}$ also seemed to result in a delay in larval death; however, in this case, the difference reported was not statistically significant $(p=0.1436)$. AqdC and AqdC VIII did not reduce the mortality of $G$. mellonella in response to $P$. aeruginosa infection, and $P$. aeruginosa$\mathrm{AqdC}^{\mathrm{V}}$ suspensions were even more detrimental for the survival of $G$. mellonella larvae than P. aeruginosa in PBS. Due to its low catalytic activity, a considerably higher amount of $\mathrm{AqdC}^{\mathrm{V}}$ protein was required to adjust the enzyme units chosen for the treatment. Control experiments revealed that injection of this dose of $\mathrm{AqdC}^{\mathrm{V}}$ protein into larvae induced melanization and led to $86.7 \%$ larvae survival after $72 \mathrm{~h}$ of incubation, while no dead 
larvae were observed after injecting the corresponding units of $\mathrm{HQD}_{N . f .}, \mathrm{HQD}_{\text {S.b., }} \mathrm{AqdC}$, or $\mathrm{AqdC}^{\mathrm{VIII}}$ protein, or $\mathrm{AqdC}$ at a 10-fold lower dose (15 larvae per condition; Figure S2a). Therefore, it seems that the effect of the P. aeruginosa-AqdC ${ }^{\mathrm{V}}$ suspension shown in Figure $5 \mathrm{~b}$ is due to toxicity of the protein at such a high load.
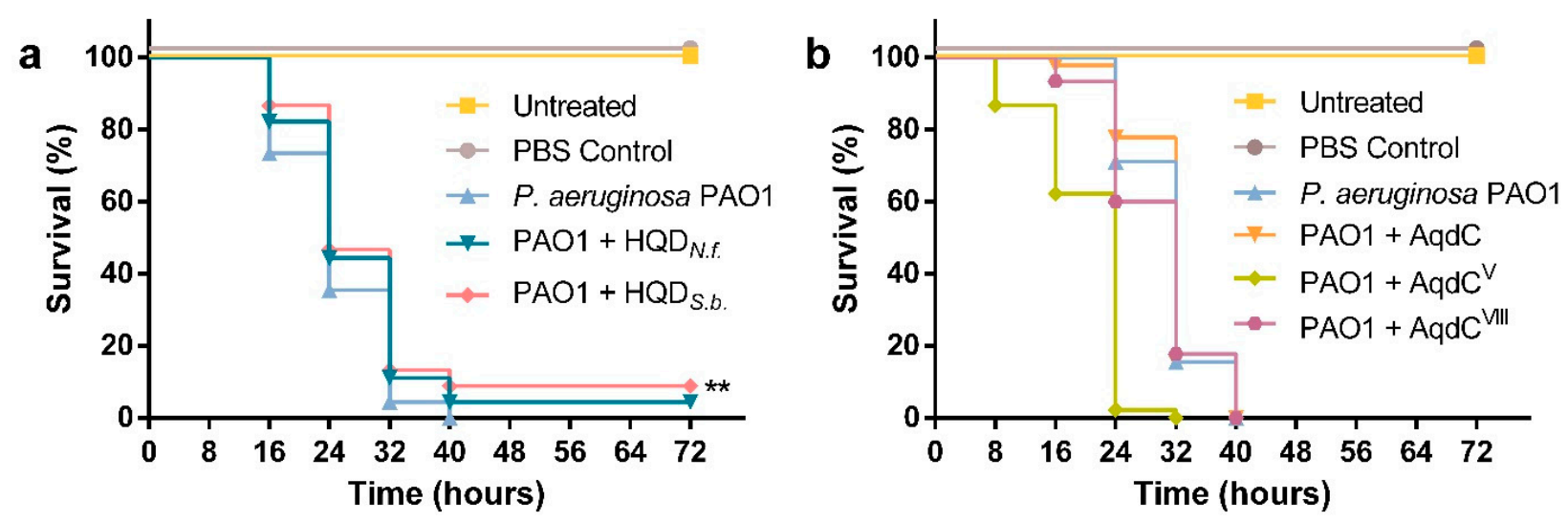

Figure 5. Effect of PQS dioxygenases on the survival of G. mellonella larvae infected with P. aeruginosa. Larvae were infected with $10 \mu \mathrm{L}$ cell suspension of $P$. aeruginosa PAO1 $\left(10^{3} \mathrm{CFU} / \mathrm{mL}\right)$, treated with (a) $\mathrm{HQD}_{N . f .}$ or $\mathrm{HQD}_{\text {S.b. }}(20 \mathrm{U} / \mathrm{mL})$, or $(\mathbf{b}) \mathrm{AqdC}, \mathrm{AqdC}^{\mathrm{VIII}}$ or $\mathrm{AqdC}^{\mathrm{V}}(20 \mathrm{U} / \mathrm{mL})$ for $1 \mathrm{~h}$ prior to injection of the suspension. Untreated larvae and larvae injected with the equivalent volume of PBS were included as controls. After inoculation, larvae were incubated at $30{ }^{\circ} \mathrm{C}$ in the dark and monitored every $8 \mathrm{~h}$ over an $80 \mathrm{~h}$ period. Kaplan-Meyer curves represent the results derived from three independent experiments with 15 larvae per condition $(n=45) .{ }^{* *}$ Indicates significant differences in larvae survival in comparison with the P. aeruginosa PAO1 infected control $(p<0.05, \log$-rank (Mantel-Cox) test).

To compare the in vivo effect of PQS dioxygenases, which despite efficient cleavage of PQS only partially attenuate AQ production, to that of specific inhibitors of AQ biosynthesis, infection model experiments were also performed with PqsD inhibitors developed by R.W. Hartmann and coworkers. PqsD is an early enzyme in AQ biosynthesis, catalyzing the decarboxylative condensation of coenzyme A-activated anthranilic acid with malonyl-CoA. Compound 19 ((2-nitrophenyl)(phenyl)methanol) previously was reported to strongly reduce both HHQ and PQS levels in P. aeruginosa [20], and compound 62 ((2-nitrophenyl)(thiophen-3-yl)methanol) was the most potent inhibitor of cellular HHQ formation among a series of derivatives based on the (2-nitrophenyl)methanol scaffold [21]. The compounds did not affect the viability of G. mellonella larvae at the concentration used for the assays (Figure S2b). In comparison with larvae infected with untreated P. aeruginosa, an increase in survival was observed for larvae infected with bacterial suspensions incubated with compound $19(p=0.04830)$ or compound $62(p=0.0203)$ (Figure 6), confirming that the inhibition of PqsD is a pertinent approach to interfere with AQ-mediated QS mechanisms. 


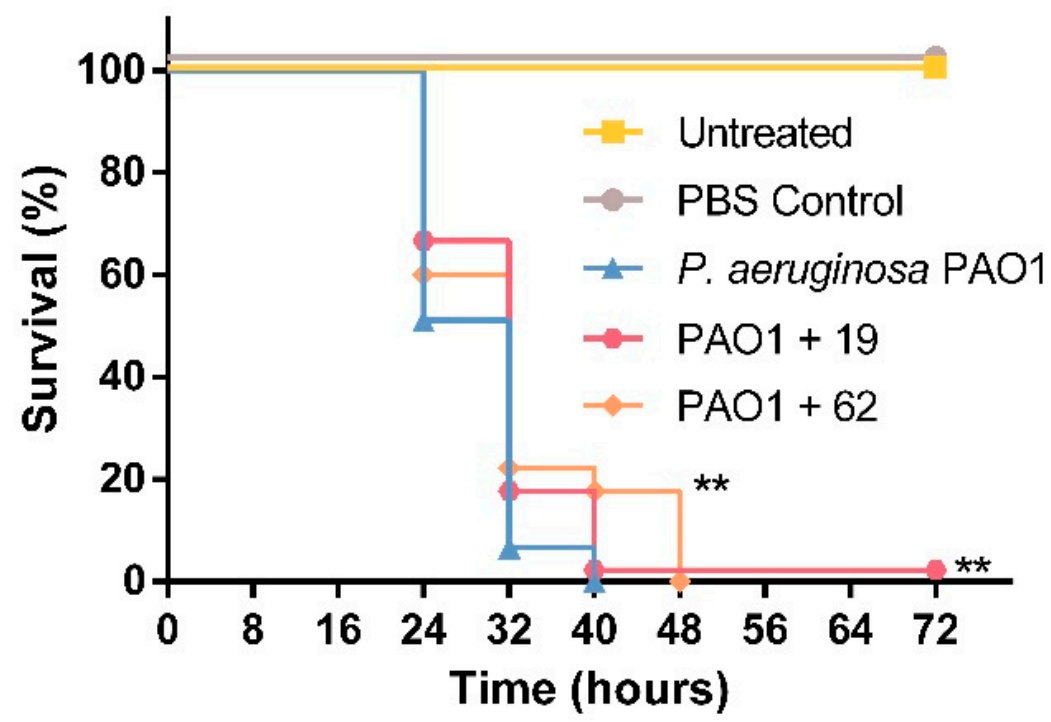

Figure 6. Effect of PqsD inhibitors $[20,21]$ on the survival of G. mellonella larvae infected with P. aeruginosa. Larvae were infected with $10 \mu \mathrm{L}$ cell suspension of P. aeruginosa PAO1, pre-incubated with compound 19 or $62(100 \mu \mathrm{M})$ for $1 \mathrm{~h}$ prior to injection. Untreated larvae and larvae injected with PBS were included as controls. Post-inoculation, larvae were incubated at $30{ }^{\circ} \mathrm{C}$ in the dark and monitored every $8 \mathrm{~h}$. Kaplan-Meyer curves represent the results obtained from three independent experiments with 15 larvae per condition $(n=45) .{ }^{* *}$ Indicates significant differences in larvae survival in comparison with the P. aeruginosa PAO1 infected control ( $p<0.05$, log-rank (Mantel-Cox) test).

\section{Discussion}

The emergence and spread of antibiotic-resistant $P$. aeruginosa strains, especially in healthcare-associated environments, such as intensive care units, results in a drastic reduction of the effective treatment options for this opportunistic pathogen. As a result, alternative approaches to combat $P$. aeruginosa infections are under ongoing investigation, particularly those aiming at reducing the virulence of this pathogen. In contrast to conventional antimicrobial agents that impose high selective pressures on bacteria, interfering with QS signaling targets bacterial pathogenesis rather than bacterial growth. The use of QQ enzymes that inactivate extracellular signals is considered to exert less evolutionary pressure toward the development of resistance mechanisms than the use of antimicrobials or of anti-virulence compounds that act intracellularly. The PQS signal constitutes a highly specific target to address P. aeruginosa because PQS signaling seems to be quite unique for this pathogen. Besides P. aeruginosa, the marine bacterium Pelagibaca bermudensis was reported to produce PQS besides other AQs [29], while other known AQ producers, such as Burkholderia spp., do not form PQS [30]. The detection of PQS in sputum, bronchoalveolar lavage, mucopurulent fluid, blood, and urine of $P$. aeruginosa-infected CF patients [31-33], as well as necrotic muscle tissue from burn wounds [34] moreover suggests that AQ-dependent QS is functional during infection.

In this study, the naturally occurring dioxygenase $\mathrm{HQD}_{N . f .}$ has been shown to have the highest catalytic activity among the PQS dioxygenases tested, in conjunction with high affinity toward the substrate, as well as high thermal stability, making this candidate most promising for potential applications or further improvements. $\mathrm{HQD}_{S . b .}$, which is also characterized by high affinity toward PQS, is of special interest due to its stabilization by $P$. aeruginosa supernatant, an observation requiring further investigation.

Interfering with the $p q s$ QS system appears to hold potential as an anti-virulence approach since PQS-cleaving dioxygenases, especially $\mathrm{HQD}_{\text {S.b. }}$, as well as PqsD inhibitors, were able to attenuate virulence factor production by P. aeruginos $a$ and to delay its lethal effects in G. mellonella larvae. However, our data also show that enzymatic degradation of the PQS signal, albeit significantly reducing HHQ and HQNO production, does not 
fully quench AQ biosynthesis in P. aeruginosa. Moreover, inactivation of the PQS signal hardly affected elastase and rhamnolipid production, which is consistent with the notion that these factors, even though the pqs system contributes to their regulation (reviewed in [35]), are mainly controlled by the las and $r h l$ circuits, respectively [36]. Enzymatic PQS cleavage inactivates not only a QS signal but also removes an iron trap, suggesting that quenching of pyoverdine levels may also be governed by increased iron availability, as already indicated by the study of Tettmann et al. [24].

Besides residual virulence factors still produced by HQD-treated P. aeruginosa, residual levels of HHQ and especially of the cytotoxic HQNO may take part in the killing of G. mellonella larvae. The PqsD inhibitors, which address an early step of the AQ biosynthetic pathway, should reduce the levels of all $A Q$ and $A Q-N$-oxide congeners to a similar extent. The reduced background of cytotoxic metabolites when P. aeruginosa is treated with PqsD inhibitors may contribute to their beneficial effect on the survival of G. mellonella.

Even though an infection may not be prevented by QQ enzymes, delaying its development might allow the infected host immune system to clear the pathogen. However, despite efficient quenching of the PQS signal itself, the effects of PQS dioxygenases on $P$. aeruginosa virulence were moderate, suggesting that for $P$. aeruginosa, which regulates its virulence via a highly complex QS network, an efficient anti-virulence therapy likely requires a combination of agents that address multiple targets.

Supplementary Materials: The following supporting information can be downloaded at https:/ / www.mdpi.com/article/10.3390/biom12020170/s1, Figure S1: SDS-PAGE analysis of purified HQD proteins. Figure S2: Effect of PQS dioxygenases and PqsD inhibitors on survival of Galleria mellonella larvae. Table S1: Kinetic parameters of HQDs for 2-heptyl-3-hydroxy-4(1H)-quinolone PQS).

Author Contributions: Conceptualization, A.A.S.M. and S.F.; methodology, A.A.S.M., J.V. and S.C.W.; investigation, A.A.S.M.; resources, S.F. and W.J.Q.; data analysis and curation, A.A.S.M.; writingoriginal draft preparation, A.A.S.M.; writing-review and editing, A.A.S.M., J.V., W.J.Q. and S.F.; supervision, S.F. and W.J.Q.; funding acquisition, S.F. and W.J.Q. All authors have read and agreed to the published version of the manuscript.

Funding: This research was funded by the European Union's Horizon 2020 research and innovation program under the Marie Skłodowska-Curie grant agreement No. 722390 and the ALERT COFUND project (EU grant agreement No. 713482).

Institutional Review Board Statement: Not applicable.

Informed Consent Statement: Not applicable.

Data Availability Statement: The data presented in this study are available in the Figures of the article and the Supplementary Materials. Strains are available upon request from the corresponding author.

Acknowledgments: We thank R.W. Hartmann and M. Empting (Helmholtz-Institute for Pharmaceutical Research Saarland (HIPS)) for kindly providing PqsD inhibitor compounds, and A. Kappius (Münster) for technical assistance. We acknowledge support from the Open Access Publication Fund of the University of Münster.

Conflicts of Interest: The authors declare no conflict of interest.

\section{References}

1. Lyczak, J.B.; Cannon, C.L.; Pier, G.B. Establishment of Pseudomonas aeruginosa infection: Lessons from a versatile opportunist. Microbes Infect. 2000, 2, 1051-1060. [CrossRef]

2. Jurado-Martín, I.; Sainz-Mejías, M.; McClean, S. Pseudomonas aeruginosa: An audacious pathogen with an adaptable arsenal of virulence factors. Int. J. Mol. Sci. 2021, 22, 3128. [CrossRef]

3. Potron, A.; Poirel, L.; Nordmann, P. Emerging broad-spectrum resistance in Pseudomonas aeruginosa and Acinetobacter baumannii: Mechanisms and epidemiology. Int. J. Antimicrob. Agents 2015, 45, 568-585. [CrossRef] [PubMed]

4. Papenfort, K.; Bassler, B.L. Quorum sensing signal-Response systems in Gram-negative bacteria. Nat. Rev. Microbiol. 2016, 14, 576-588. [CrossRef]

5. Nadal Jimenez, P.; Koch, G.; Thompson, J.A.; Xavier, K.B.; Cool, R.H.; Quax, W.J. The multiple signaling systems regulating virulence in Pseudomonas aeruginosa. Microbiol. Mol. Biol. Rev. 2012, 76, 46-65. [CrossRef] 
6. $\quad$ Diggle, S.P.; Matthijs, S.; Wright, V.J.; Fletcher, M.P.; Chhabra, S.R.; Lamont, I.L.; Kong, X.; Hider, R.C.; Cornelis, P.; Cámara, M.; et al. The Pseudomonas aeruginosa 4-quinolone signal molecules HHQ and PQS play multifunctional roles in quorum sensing and iron entrapment. Chem. Biol. 2007, 14, 87-96. [CrossRef] [PubMed]

7. Lin, J.; Cheng, J.; Wang, Y.; Shen, X. The Pseudomonas quinolone signal (PQS): Not just for quorum sensing anymore. Front. Cell. Infect. Microbiol. 2018, 8, 1-9. [CrossRef]

8. Bru, J.L.; Rawson, B.; Trinh, C.; Whiteson, K.; Høyland-Kroghsbo, N.M.; Siryaporn, A. PQS produced by the Pseudomonas aeruginosa stress response repels swarms away from bacteriophage and antibiotics. J. Bacteriol. 2019, 201, e00383-19. [CrossRef]

9. Reen, F.J.; Mooij, M.J.; Holcombe, L.J.; McSweeney, C.M.; McGlacken, G.P.; Morrissey, J.P.; O'Gara, F. The Pseudomonas quinolone signal (PQS), and its precursor HHQ, modulate interspecies and interkingdom behaviour. FEMS Microbiol. Ecol. 2011, 77, 413-428. [CrossRef] [PubMed]

10. Hazan, R.; Que, Y.A.; Maura, D.; Strobel, B.; Majcherczyk, P.A.; Hopper, L.R.; Wilbur, D.J.; Hreha, T.N.; Barquera, B.; Rahme, L.G. Auto poisoning of the respiratory chain by a quorum-sensing-regulated molecule favors biofilm formation and antibiotic tolerance. Curr. Biol. 2016, 26, 195-206. [CrossRef]

11. Kaufmann, G.F.; Park, J.; Janda, K.D. Bacterial quorum sensing: A new target for anti-infective immunotherapy. Expert Opin. Biol. Ther. 2008, 8, 719-724. [CrossRef]

12. Grandclément, C.; Tannières, M.; Moréra, S.; Dessaux, Y.; Faure, D. Quorum quenching: Role in nature and applied developments FEMS Microbiol. Rev. 2015, 40, 86-116. [CrossRef]

13. Fetzner, S. Quorum quenching enzymes. J. Biotechnol. 2014, 201, 2-14. [CrossRef]

14. Wullich, S.C.; Arranz San Martín, A.; Fetzner, S. Definition of an $\alpha / \beta$-hydrolase fold subfamily comprising Pseudomonas quinolone signal cleaving dioxygenases. Appl. Environ. Microbiol. 2020, 86, e00279-20. [CrossRef] [PubMed]

15. Pustelny, C.; Albers, A.; Büldt-Karentzopoulos, K.; Parschat, K.; Chhabra, S.R.; Cámara, M.; Williams, P.; Fetzner, S. Dioxygenasemediated quenching of quinolone-dependent quorum sensing in Pseudomonas aeruginosa. Chem. Biol. 2009, 16, $1259-1267$. [CrossRef] [PubMed]

16. Birmes, F.S.; Säring, R.; Hauke, M.C.; Ritzmann, N.H.; Drees, S.L.; Daniel, J.; Treffon, J.; Liebau, E.; Kahl, B.C.; Fetzner, S Interference with Pseudomonas aeruginosa quorum sensing and virulence by the mycobacterial PQS dioxygenase AqdC in combination with the $N$-acylhomoserine lactone lactonase QsdA. Infect. Immun. 2019, 87, e00278-19. [CrossRef] [PubMed]

17. Müller, C.; Birmes, F.S.; Rückert, C.; Kalinowski, J.; Fetzner, S. Rhodococcus erythropolis BG43 genes mediating Pseudomonas aeruginosa quinolone signal degradation and virulence factor attenuation. Appl. Environ. Microbiol. 2015, 81, 7720-7729. [CrossRef]

18. Birmes, F.S.; Wolf, T.; Kohl, T.A.; Rüger, K.; Bange, F.; Kalinowski, J.; Fetzner, S. Mycobacterium abscessus subsp. abscessus is capable of degrading Pseudomonas aeruginosa quinolone signals. Front. Microbiol. 2017, 8, 339. [CrossRef] [PubMed]

19. Wullich, S.C.; Wijma, H.J.; Janssen, D.B.; Fetzner, S. Stabilizing AqdC, a Pseudomonas quinolone signal-cleaving dioxygenase from Mycobacteria, by FRESCO-based protein engineering. ChemBioChem 2020, 22, 733-742. [CrossRef]

20. Storz, M.P.; Maurer, C.K.; Zimmer, C.; Wagner, N.; Brengel, C.; De Jong, J.C.; Lucas, S.; Müsken, M.; Häussler, S.; Steinbach, A.; et al. Validation of PqsD as an anti-biofilm target in Pseudomonas aeruginosa by development of small-molecule inhibitors. J. Am. Chem. Soc. 2012, 134, 16143-16146. [CrossRef]

21. Storz, M.P.; Allegretta, G.; Kirsch, B.; Empting, M.; Hartmann, R.W. From in vitro to in cellulo: Structure-activity relationship of (2-nitrophenyl)methanol derivatives as inhibitors of PqsD in Pseudomonas aeruginosa. Org. Biomol. Chem. 2014, 12, 6094-6104. [CrossRef]

22. Studier, F.W.; Moffatt, B.A. Use of bacteriophage T7 RNA polymerase to direct selective high-level expression of cloned genes. J. Mol. Biol. 1986, 189, 113-130. [CrossRef]

23. Rahme, L.G.; Stevens, E.J.; Wolfort, S.F.; Shao, J.; Tompkins, R.G.; Ausubel, F.M. Common virulence factors for bacterial pathogenicity in plants and animals. Science 1995, 268, 1899-1902. [CrossRef]

24. Tettmann, B.; Niewerth, C.; Kirschhöfer, F.; Neidig, A.; Dötsch, A.; Brenner-Weiss, G.; Fetzner, S.; Overhage, J. Enzyme-mediated quenching of the Pseudomonas quinolone signal (PQS) promotes biofilm formation of Pseudomonas aeruginosa by increasing iron availability. Front. Microbiol. 2016, 7, 1978. [CrossRef] [PubMed]

25. Essar, D.W.; Eberly, L.; Hadero, A.; Crawford, I.P. Identification and characterization of genes for a second anthranilate synthase in Pseudomonas aeruginosa: Interchangeability of the two-anthranilate synthase and evolutionary implications. J. Bacteriol. 1990, 172, 884-900. [CrossRef]

26. Stintzi, A.; Cornelis, P.; Hohnadel, D.; Meyer, J.M.; Dean, C.; Poole, K.; Kourambas, S.; Krishnapillai, V. Novel pyoverdine biosynthesis gene(s) of Pseudomonas aeruginosa PAO. Microbiology 1996, 142, 1181-1190. [CrossRef] [PubMed]

27. Wilhelm, S.; Gdynia, A.; Tielen, P.; Rosenau, F.; Jaeger, K.E. The autotransporter esterase EstA of Pseudomonas aeruginosa is required for rhamnolipid production, cell motility, and biofilm formation. J. Bacteriol. 2007, 189, 6695-6703. [CrossRef] [PubMed]

28. Toder, D.S.; Gambello, M.J.; Iglewski, B.H. Pseudomonas aeruginosa LasA: A second elastase under the transcriptional control of lasR. Mol. Microbiol. 1991, 5, 2003-2010. [CrossRef]

29. Patidar, S.K.; Kim, S.H.; Kim, J.H.; Park, J.; Park, B.S.; Han, M.S. Pelagibaca bermudensis promotes biofuel competence of Tetraselmis striata in a broad range of abiotic stressors: Dynamics of quorum-sensing precursors and strategic improvement in lipid productivity. Biotechnol. Biofuels 2018, 11, 1-16. [CrossRef] 
30. Coulon, P.M.L.; Zlosnik, J.E.A.; Déziel, E. Presence of the Hmq system and production of 4-hydroxy-3-methyl-2-alkylquinolines are heterogeneously distributed between Burkholderia cepacia complex species and more prevalent among environmental than clinical isolates. Microbiol. Spectr. 2021, 9, e00127-21. [CrossRef]

31. Collier, D.N.; Anderson, L.; McKnight, S.L.; Noah, T.L.; Knowles, M.; Boucher, R.; Schwab, U.; Gilligan, P.; Pesci, E.C. A bacterial cell to cell signal in the lungs of cystic fibrosis patients. FEMS Microbiol. Lett. 2002, 215, 41-46. [CrossRef] [PubMed]

32. Abdalla, M.Y.; Hoke, T.; Seravalli, J.; Switzer, B.L.; Bavitz, M.; Fliege, J.D.; Murphy, P.J.; Britigan, B.E. Pseudomonas aeruginosa signal induces oxidative stress and inhibits heme oxygenase-1 expression in lung epithelial cells. Infect. Immun. 2017, 85, e00176-17. [CrossRef] [PubMed]

33. Barr, H.L.; Halliday, N.; Barrett, D.A.; Williams, P.; Forrester, D.L.; Peckham, D.; Williams, K.; Smyth, A.R.; Honeybourne, D.L.; Whitehouse, J.; et al. Diagnostic and prognostic significance of systemic alkyl quinolones for P. aeruginosa in cystic fibrosis: A longitudinal study. J. Cyst. Fibros. 2017, 16, 230-238. [CrossRef] [PubMed]

34. Que, Y.-A.; Hazan, R.; Ryan, C.M.; Milot, S.; Lépine, F.; Lydon, M.; Rahme, L.G. Production of Pseudomonas aeruginosa intercellular small signaling molecules in human burn wounds. J. Pathog. 2011, 2011, 1-5. [CrossRef] [PubMed]

35. Garcia-Reyes, S.; Soberón-Chávez, G.; Cocotl-Yanez, M. The third quorum-sensing system of Pseudomonas aeruginosa: Pseudomonas quinolone signal and the enigmatic PqsE protein. J. Med. Microbiol. 2020, 69, 25-34. [CrossRef]

36. Pearson, J.P.; Pesci, E.C.; Iglewski, B.H. Roles of Pseudomonas aeruginosa las and rhl quorum-sensing systems in control of elastase and rhamnolipid biosynthesis genes. J. Bacteriol. 1997, 179, 5756-5767. [CrossRef] 